\title{
Prognostic Factors in Patients With Recurrent Pancreatic Cancer: A Multicenter Database Analysis
}

\author{
KENEI FURUKAWA ${ }^{1}$, HIROAKI SHIBA ${ }^{1}$, RYOGA HAMURA ${ }^{1}$, KOICHIRO HARUKI ${ }^{1}$, \\ YUKI FUJIWARA ${ }^{1}$, TERUYUKI USUBA ${ }^{2}$, YUKIO NAKABAYASHI ${ }^{3}$, TAKEYUKI MISAWA ${ }^{4}$, \\ TOMOYOSHI OKAMOTO ${ }^{5}$ and KATSUHIKO YANAGA ${ }^{1}$ \\ ${ }^{1}$ Department of Surgery, The Jikei University School of Medicine, Tokyo, Japan; \\ ${ }^{2}$ Department of Surgery, The Jikei University Katsushika Medical Center, Tokyo, Japan; \\ ${ }^{3}$ Department of Surgery, The Kawaguchi Municipal Medical Center, Saitama, Japan; \\ ${ }^{4}$ Department of Surgery, The Jikei University Kashiwa Hospital, Chiba, Japan; \\ ${ }^{5}$ Department of Surgery, The Jikei University Daisan Hospital, Tokyo, Japan
}

\begin{abstract}
Background/Aim: The prognosis of pancreatic cancer remains poor with a high incidence of recurrence even after curative resection. The aim of this study was to investigate prognostic factors in patients with recurrent pancreatic cancer using the multicenter database. Patients and Methods: The subjects were 196 patients with recurrent pancreatic cancer who underwent resection between 2008 and 2015. We retrospectively investigated the relation between clinicopathological characteristics of the patients and overall survival from recurrence using univariate and multivariate analyses. Results: In univariate analysis, the positive lymphatic invasion $(p=0.0240)$, time to recurrence from resection $<1$ year $(p<0.0001)$, sites of recurrence except for local or lymph node ( $p=0.0273)$, liver recurrence $(p=0.0389)$ and peritoneal recurrence $(p<0.0001)$ were significantly associated with poor overall survival from recurrence. In multivariate analysis, time to recurrence from resection $<1$ year $(p<0.0001)$ and peritoneal recurrence $(p<0.0001)$ were independently associated with poor overall survival from recurrence. Conclusion: Time to recurrence from resection $<1$ year and peritoneal recurrence were significant independent predictors of poor overall survival from recurrence in patients with recurrent pancreatic cancer.
\end{abstract}

Pancreatic cancer is currently the fourth leading cause of cancer death worldwide (1). Despite improvements in

Correspondence to: Kenei Furukawa, The Jikei University School of Medicine, 3-25-8, Nishi-Shinbashi, Minato-ku, Tokyo 105-8461, Japan. Tel: +81 334331111 ext.3401, Fax: +81 334358677, e-mail: k-furukawa@jikei.ac.jp

Key Words: Prognostic factor, recurrent pancreatic cancer, peritoneal recurrence. surgical techniques, chemotherapy and follow-up methodology, pancreatic cancer remains a fatal disease, with a global 5-year survival rate of less than $10 \%$ (1). The majority of patients with pancreatic cancer present with locally advanced or metastatic disease, and less than $20 \%$ of patients are fit for resection at the time of diagnosis (2). Surgical resection is still considered the only potentially curative treatment for pancreatic cancer, but approximately $80 \%$ of surgically resected pancreatic cancer recur within 5 years, and over $60 \%$ of patients develop recurrences within 2 years (3). Therefore, identifying poor prognostic factors that may predict the tumor recurrence and prognosis of patients is important for selecting appropriate treatment.

There have been reports identifying prognostic factors for pancreatic cancer (4), but most previous studies were based on surgically resected or heterogeneous unresectable including metastatic and recurrent pancreatic cancer. It is therefore worthy to identify prognostic factors in patients who developed recurrent pancreatic cancer.

Here, we retrospectively performed a prognostic factor analysis using a multicenter database in patients with recurrence after surgical resection for pancreatic cancer.

\section{Patients and Methods}

Between 2008 and 2015, a total of 332 patients with pancreatic cancer underwent pancreatic resection at four university hospitals (The Jikei University Hospital, Katsushika Medical Center, Daisan Hospital and Kashiwa Hospital) and an associated facility (The Kawaguchi Municipal Medical Center). Of these, recurrence was observed in 236 patients. We excluded 40 patients from the analysis for the following reasons: 2 with anaplastic cancer and 38 due to lack of data. Finally, 196 patients were included in the final analysis.

Tumor-nodes-metastasis (TNM) staging was based on the eighth edition of the Union for International Cancer Control (UICC) (5). Postoperatively, the patients received adjuvant chemotherapy using 
gemcitabine, S-1 or gemcitabine and intra-arterial transfusion of nafamostat mesylate (6), excluding the patients with poor performance status or those who refused treatment. Tumor recurrence was defined as newly detected local or distant metastatic tumors based on the findings of ultrasonography, computed tomography, or magnetic resonance imaging with or without increased serum carcinoembryonic antigen or carbohydrate antigen 19-9 (CA19-9) levels. When multiple sites of recurrence were detected simultaneously, each site was counted. For recurrence, chemotherapy or conversion to another chemotherapy were chosen based on performance status.

At first, we retrospectively investigated the relation between patient characteristics and overall survival from recurrence in patients with recurrent pancreatic cancer by univariate and multivariate analyses. The factors included age, gender, operative time, intraoperative blood loss, tumor position, tumor differentiation, lymphatic invasion, venous invasion, TNM classification, curability, time to recurrence from resection and sites of recurrence.

Next, we compared time to recurrence from resection $\geq 1$ year and $<1$ year using the following factors: age, gender, operative time, intraoperative blood loss, tumor location, tumor differentiation, lymphatic invasion, venous invasion, neural invasion, TNM classification, curability and sites of recurrence. We then analyzed patient characteristics in relation to peritoneal recurrence using the following factors: age, gender, operative time, intraoperative blood loss, tumor location, tumor differentiation, lymphatic invasion, venous invasion, neural invasion, TNM classification, curability and time to recurrence from resection.

This study was approved by the Ethics Committee of the Jikei University School of Medicine (30-322).

Statistical analysis. The data were expressed as a mean \pm standard deviation (SD). Univariate analyses were performed using the logrank test, non-paired $t$-test and Chi-square test. Multivariate analysis was performed using the Cox proportional regression model. Survival rates were calculated by the Kaplan-Meier method. All $p$ values were considered statistically significant when the associated probability was less than 0.05 .

\section{Results}

Patient characteristics and overall survival from recurrence by univariate and multivariate analyses. Characteristics of the patients are summarized in Table I. Tables II and III list the relationship between patient characteristics and overall survival from recurrence in patients that underwent resection for pancreatic cancer. In univariate analysis, the positive lymphatic invasion $(p=0.0240)$, time to recurrence from resection $<1$ year $(p<0.0001$, Figure $1 \mathrm{~A})$, sites of recurrence except for local or lymph node $(p=0.0273)$, liver recurrence $(p=0.0389)$ and peritoneal recurrence $(p<0.0001$, Figure 1B) were significantly associated with poor overall survival from recurrence. In multivariate analysis, time to recurrence from resection $<1$ year $(p<0.0001)$ and peritoneal recurrence $(p<0.0001)$ were independently associated with poor overall survival from recurrence.

Association between patient characteristics and time to recurrence from resection. Table IV lists the association
Table I. Patient characteristics.

\begin{tabular}{|c|c|c|}
\hline Factor & Median or number & Range or $\%$ \\
\hline Age (years) & 69.5 & $38-87$ \\
\hline \multicolumn{3}{|l|}{ Gender } \\
\hline Male & 115 & $59 \%$ \\
\hline Female & 81 & $41 \%$ \\
\hline \multicolumn{3}{|l|}{ Tumor location } \\
\hline Pancreatic head & 131 & $67 \%$ \\
\hline Pancreatic body or tail & 65 & $33 \%$ \\
\hline Operative time (min) & 462.5 & $150-992$ \\
\hline Intraoperative blood loss (ml) & 758 & $0-21,080$ \\
\hline \multicolumn{3}{|l|}{ Tumor differentiation } \\
\hline Well & 61 & $31 \%$ \\
\hline Moderately & 122 & $62 \%$ \\
\hline Poorly & 13 & $7 \%$ \\
\hline \multicolumn{3}{|l|}{ Lymphatic invasion } \\
\hline Negative & 47 & $24 \%$ \\
\hline Positive & 149 & $76 \%$ \\
\hline \multicolumn{3}{|l|}{ Venous invasion } \\
\hline Negative & 72 & $37 \%$ \\
\hline Positive & 124 & $63 \%$ \\
\hline \multicolumn{3}{|l|}{ Neural invasion } \\
\hline Negative & 34 & $17 \%$ \\
\hline Positive & 162 & $83 \%$ \\
\hline \multicolumn{3}{|l|}{ TNM classification } \\
\hline I & 43 & $22 \%$ \\
\hline II & 114 & $58 \%$ \\
\hline III & 33 & $17 \%$ \\
\hline IV & 6 & $3 \%$ \\
\hline \multicolumn{3}{|l|}{ Curability } \\
\hline R0 & 149 & $76 \%$ \\
\hline $\mathrm{R} 1$ or 2 & 47 & $24 \%$ \\
\hline \multicolumn{3}{|l|}{$\begin{array}{l}\text { Time to recurrence from } \\
\text { resection (year) }\end{array}$} \\
\hline$\geq 1$ & 66 & $34 \%$ \\
\hline$<1$ & 130 & $66 \%$ \\
\hline \multicolumn{3}{|l|}{ Site of recurrence } \\
\hline Local or lymph node & 86 & $44 \%$ \\
\hline Liver & 66 & $34 \%$ \\
\hline Peritoneum & 32 & $16 \%$ \\
\hline Lung & 25 & $13 \%$ \\
\hline
\end{tabular}

TNM: Tumor-nodes-metastasis; R0: microscopic curative resection; R1: microscopic residual tumor; R2: macroscopic residual tumor.

between patient characteristics and time to recurrence from resection. In time to recurrence from resection <1-year group, lymphatic invasion and liver recurrence were significantly more frequent than in those in time to recurrence from resection $\geq 1$-year group ( $p=0.0038$ and 0.0085 , respectively).

Association between patient characteristics and peritoneal recurrence. Table $\mathrm{V}$ lists the association between patient characteristics and peritoneal recurrence. In the peritoneal recurrence present group, intraoperative blood loss, well differentiated tumor and venous invasion were significantly more frequent than in those in the peritoneal recurrence absent group ( $p=0.0408,0.0033$ and 0.0211 , respectively). 
Table II. Univariate analysis of overall survival from recurrence for pancreatic cancer

\begin{tabular}{|c|c|c|c|}
\hline \multirow[t]{2}{*}{ Factor } & \multirow[t]{2}{*}{$\mathrm{N}$} & \multicolumn{2}{|c|}{ Overall survival from recurrence } \\
\hline & & Median (years) & $p$-Value \\
\hline \multicolumn{4}{|l|}{ Age (years) } \\
\hline$\geq 70$ & 97 & 0.48 & \multirow[t]{2}{*}{0.5414} \\
\hline$<70$ & 99 & 0.55 & \\
\hline \multicolumn{4}{|l|}{ Gender } \\
\hline Male & 115 & 0.55 & \multirow[t]{2}{*}{0.6372} \\
\hline Female & 81 & 0.45 & \\
\hline \multicolumn{4}{|l|}{ Operative time (min) } \\
\hline$\geq 500$ & 70 & 0.53 & \multirow[t]{2}{*}{0.4859} \\
\hline$<500$ & 126 & 0.52 & \\
\hline \multicolumn{4}{|l|}{$\begin{array}{l}\text { Intraoperative blood loss } \\
(\mathrm{mL})\end{array}$} \\
\hline$\geq 1,000$ & 76 & 0.43 & \multirow[t]{2}{*}{0.0771} \\
\hline$<1,000$ & 120 & 0.59 & \\
\hline \multicolumn{4}{|l|}{ Tumor location } \\
\hline Pancreatic head & 131 & 0.45 & \multirow[t]{2}{*}{0.0810} \\
\hline Pancreatic body or tail & 65 & 0.57 & \\
\hline \multicolumn{4}{|l|}{ Tumor differentiation } \\
\hline Well & 61 & 0.67 & \multirow[t]{3}{*}{0.1277} \\
\hline Moderately & 122 & 0.45 & \\
\hline Poorly & 13 & 0.51 & \\
\hline \multicolumn{4}{|l|}{ Lymphatic invasion } \\
\hline Negative & 47 & 0.60 & \multirow[t]{2}{*}{0.0240} \\
\hline Positive & 149 & 0.48 & \\
\hline \multicolumn{4}{|l|}{ Venous invasion } \\
\hline Negative & 72 & 0.47 & \multirow[t]{2}{*}{0.4797} \\
\hline Positive & 124 & 0.55 & \\
\hline \multicolumn{4}{|l|}{ Neural invasion } \\
\hline Negative & 34 & 0.38 & \multirow[t]{2}{*}{0.2474} \\
\hline Positive & 162 & 0.56 & \\
\hline \multicolumn{4}{|l|}{ TNM classification } \\
\hline I or II & 157 & 0.48 & 0.6078 \\
\hline III or IV & 39 & 0.57 & \\
\hline Curability & & & \\
\hline R0 & 149 & 0.55 & 0.2401 \\
\hline $\mathrm{R} 1$ or 2 & 47 & 0.39 & \\
\hline $\begin{array}{l}\text { Time to recurrence } \\
\text { from resection (year) }\end{array}$ & & & \\
\hline$\geq 1$ & 66 & 0.89 & $<0.0001$ \\
\hline$<1$ & 130 & 0.42 & \\
\hline $\begin{array}{l}\text { Site of recurrence } \\
\text { (Local or lymph node) }\end{array}$ & & & \\
\hline Present & 86 & 0.67 & 0.0273 \\
\hline Absent & 110 & 0.41 & \\
\hline Site of recurrence (Liver) & & & \\
\hline Present & 66 & 0.40 & 0.0389 \\
\hline Absent & 130 & 0.59 & \\
\hline $\begin{array}{l}\text { Site of recurrence } \\
\text { (Peritoneum) }\end{array}$ & & & \\
\hline Present & 32 & 0.33 & $<0.0001$ \\
\hline Absent & 164 & 0.57 & \\
\hline Site of recurrence (Lung) & & & \\
\hline Present & 25 & 0.77 & 0.5294 \\
\hline Absent & 171 & 0.48 & \\
\hline
\end{tabular}

TNM: Tumor-nodes-metastasis, R0: microscopic curative resection, R1: microscopic residual tumor, R2: macroscopic residual tumor.
Table III. Multivariate analysis of overall survival from recurrence for pancreatic cancer.

\begin{tabular}{lcr}
\hline Factor & Odds ratio (95\%CI) & $p$-Value \\
\hline $\begin{array}{l}\text { Lymphatic invasion (positive) } \\
\text { Time to recurrence from }\end{array}$ & $1.427(0.938-2.172)$ & 0.0970 \\
resection (<1 year) & $2.732(1.817-4.108)$ & $<0.0001$ \\
$\begin{array}{l}\text { Site of recurrence (Local or } \\
\text { lymph node) }\end{array}$ & $1.227(0.789-1.908)$ & 0.3645 \\
$\begin{array}{l}\text { Site of recurrence (Liver) } \\
\text { Site of recurrence (Peritoneum) }\end{array}$ & $1.422(0.922-2.193)$ & 0.1116 \\
\hline
\end{tabular}

CI: Confidence interval.

\section{Discussion}

We herein demonstrated that time to recurrence from resection $<1$ year and peritoneal recurrence were independently significant predictors of poor prognosis in patients with recurrence after resection for pancreatic cancer using a multicenter database. To the best of our knowledge, there were only two reports on prognostic factors in patients with recurrent pancreatic cancer. Sakamoto, et al. reported that the combination of neutrophil-to-lymphocyte ration (NLR) and serum CA19-9 level were independent prognostic factors in 66 patients with recurrent pancreatic cancer (7). Yamada, et $a l$. reported that the performance status, invasion of lymph vessels, kind of treatment for recurrence and initial recurrence were independent significant risk factors for the survival time after recurrence in 85 patients who developed recurrence after curative surgery for pancreatic cancer (8).

Recurrence can develop at various sites including the locoregional area, liver, peritoneum and lung. The prognosis differs according to the site of recurrence because each type of recurrence is caused by different mechanisms and has its own specific characteristics (9). Kim, et al. reported that patients with peritoneal recurrence had the shortest survival and patients with lung recurrence had the longest survival (10). In the current study, patients with peritoneal recurrence had the shortest survival after recurrence.

Peritoneal recurrence is the most dismal type of recurrence in terms of symptoms and prognosis due to ascites and intestinal obstruction leading to abdominal distension (11, 12). Ariake, et al. reported that excessive blood loss, artery invasion, pancreatic nerve plexus invasion and histological grade 3 were risk factors for peritoneal recurrence (12). On the other hand, the current study interestingly showed that a well differentiated tumor was a risk factor for peritoneal recurrence, and an independent predictor for poor overall survival from recurrence. Our previous study reported that well tumor differentiation was an independent predictor for good disease-free and overall survival in patients who underwent pancreaticoduodenectomy for pancreatic cancer 
Table IV. Association between patient characteristics and time to recurrence from resection.

\begin{tabular}{lcc}
\hline Factor & \multirow{2}{*}{ Time to recurrence from resection } \\
\cline { 2 - 3 } & $\geq 1$ year (n=66) & $<$ year (n=130) \\
\hline Age (years) & $66.9 \pm 8.8$ & $69.5 \pm 9.1$ \\
Gender (Male:Female) & $41: 25$ & $74: 56$ \\
Operative time (min) & $475.1 \pm 131.9$ & $459.5 \pm 133.6$ \\
Intraoperative blood loss (ml) & $1,212.5 \pm 1,251.3$ & $1,207.7 \pm 2,001.4$ \\
Tumor position (Pancreatic head:Pancreatic body or tail) & $43: 23$ & $88: 42$ \\
Tumor differentiation (Well:Others) & $24: 42$ & $37: 93$ \\
Lymphatic invasion (Negative:Positive) & $24: 42$ & $23: 107$ \\
Venous invasion (Negative:Positive) & $27: 39$ & $45: 85$ \\
Neural invasion (Negative:Positive) & $12: 54$ & $22: 108$ \\
TNM classification (I or II:III or IV) & $58: 8$ & $99: 31$ \\
Curability (R0:R1 or 2) & $52: 14$ & $97: 33$ \\
Site of recurrence (Local or lymph node:Others) & $35: 31$ & $51: 79$ \\
Site of recurrence (Liver:Others) & $14: 52$ & $52: 78$ \\
Site of recurrence (Peritoneum:Others) & $8: 58$ & $24: 106$ \\
Site of recurrence (Lung:Others) & $8: 58$ & $17: 113$ \\
\hline
\end{tabular}

Mean \pm SD; TNM: Tumor-nodes-metastasis; R0: microscopic curative resection; R1: microscopic residual tumor; R2: macroscopic residual tumor.

A

(\%)

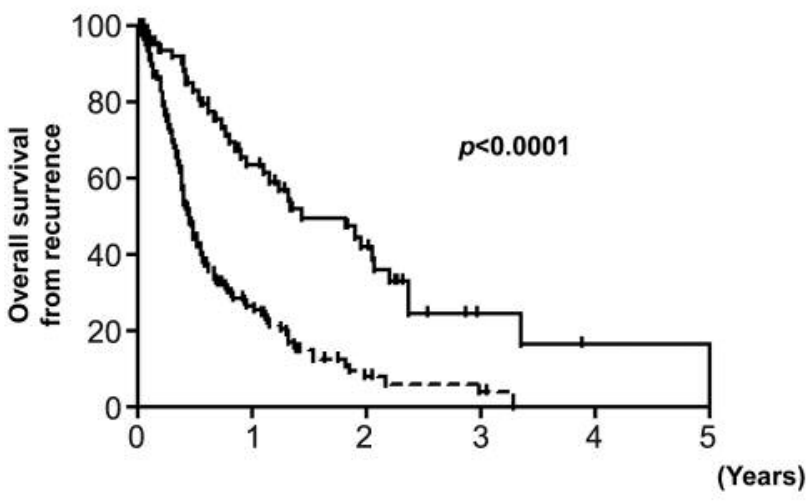

Time to recurrence from resection

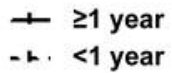

B

(\%)

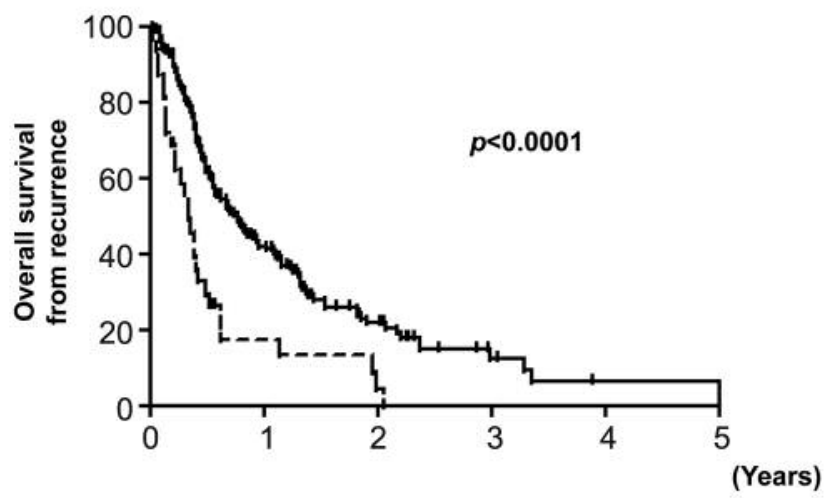

Peritoneal recurrence

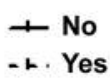

Figure 1. Kaplan-Meier curves of overall survival from recurrence in patients with time to recurrence from resection $\geq 1$ and $<1$ year (A), and those with and without peritoneal recurrence $(B)$.

(13), which could indicate that the prevention of the peritoneal recurrence in patients with a well differentiated tumor is important for better prognosis. Our multicenter database showed that overall survival rates at 1,3 and 5-year were $85.3 \%, 60.0 \%$ and $47.1 \%$ in 77 patients with well differentiated pancreatic cancer without peritoneal recurrence.

Nab-paclitaxel plus gemcitabine is one of the standard first-line systemic chemotherapy regimens for patients with metastatic pancreatic cancer (14). Paclitaxel has been shown to have a promising efficacy for gastric cancer with peritoneal metastasis (15), and nab-paclitaxel was more effective for peritoneal metastasis than paclitaxel in patients with advanced gastric cancer (16). Therefore, $n a b$-paclitaxel plus gemcitabine as adjuvant chemotherapy may prevent peritoneal recurrence in patients with resected pancreatic cancer, resulting in better prognosis. A randomized 
Table V. Association between patient characteristics and peritoneal recurrence.

\begin{tabular}{lcc}
\hline Factor & \multicolumn{2}{c}{ Peritoneal recurrence } \\
\cline { 2 - 3 } & Present (n=32) & Absent (n=164) \\
\hline Age (years) & $69.2 \pm 10.5$ & $68.5 \pm 8.8$ \\
Gender (Male:Female) & $16: 16$ & $99: 65$ \\
Operative time (min) & $446.3 \pm 160.5$ & $468.3 \pm 127.1$ \\
Intraoperative blood loss (ml) & $1,797.6 \pm 3,684.4$ & $1,094.5 \pm 1,063.7$ \\
Tumor position (Pancreatic head:Pancreatic body or tail) & $22: 10$ & $109: 55$ \\
Tumor differentiation (Well:Others) & $17: 15$ & $44: 120$ \\
Lymphatic invasion (Negative:Positive) & $7: 25$ & $40: 124$ \\
Venous invasion (Negative:Positive) & $6: 26$ & $66: 98$ \\
Neural invasion (Negative:Positive) & $6: 26$ & $28: 136$ \\
TNM classification (I or II:III or IV) & $27: 5$ & $130: 34$ \\
Curability (R0:R1 or 2) & $21: 11$ & $128: 36$ \\
Time to recurrence from resection (years) & $0.84 \pm 0.72$ & $1.04 \pm 0.91$ \\
\hline
\end{tabular}

Mean \pm SD; TNM: Tumor-nodes-metastasis; R0: microscopic curative resection; R1: microscopic residual tumor; R2: macroscopic residual tumor.

controlled study of adjuvant $n a b$-paclitaxel plus gemcitabine for resectable pancreatic cancer is now ongoing (17).

The current study had a retrospective and observational design. Furthermore, the detailed treatment for recurrence was not described due to lack of data. However, a unique strong point was that this was the first report analyzing prognostic factors for recurrent pancreatic cancer using a multicenter database.

In conclusion, time to recurrence from resection $<1$ year and peritoneal recurrence were the significant independent predictors of poor overall survival from recurrence in patients with recurrence after resection for pancreatic cancer.

\section{Conflicts of Interest}

The Authors have no conflicts of interest to declare regarding this study.

\section{Authors' Contributions}

Kenei Furukawa: Design of the study, collection and analysis of data and drafting of the article; Hiroaki Shiba: Revision of the article; Ryoga Hamura: Collection of data; Koichiro Haruki: Collection of data; Yuki Fujiwara: Collection of data; Teruyuki Usuba: Collection of data; Yukio Nakabayashi: Collection of data; Takeyuki Misawa: Collection of data; Tomoyoshi Okamoto: Collection of data; Katsuhiko Yanaga: Revision of the article and final approval of the article.

\section{References}

1 Siegel RL, Miller KD and Jemal A: Cancer Statistics, 2017. CA Cancer J Clin 67: 7-30, 2017. PMID: 28055103. DOI: 10.3322/ caac. 21387
2 Hidalgo M: Pancreatic cancer. N Engl J Med 362: 1605-1617, 2010. PMID: 20427809. DOI: 10.1056/NEJMra0901557

3 Herman JM, Swartz MJ, Hsu CC, Winter J, Pawlik TM, Sugar E, Robinson R, Laheru DA, Jaffee E, Hruban RH, Campbell KA, Wolfgang CL, Asrari F, Donehower R, Hidalgo M, Diaz LA Jr, Yeo C, Cameron JL, Schulick RD and Abrams R: Analysis of fluorouracil-based adjuvant chemotherapy and radiation after pancreaticoduodenectomy for ductal adenocarcinoma of the pancreas: results of a large, prospectively collected database at the Johns Hopkins Hospital. J Clin Oncol 26: 3503-3510, 2008. PMID: 18640931. DOI: 10.1200/JCO.2007.15.8469

4 Bilici A: Prognostic factors related with survival in patients with pancreatic adenocarcinoma. World J Gastroenterol 20: 1080210812, 2014. PMID: 25152583. DOI: 10.3748/wjg.v20.i31.10802

5 Brierley JD, Gospodarowicz MK and Wittekind C: UICC TNM Classification of malignant tumours. 8th ed. Hoboken, NJ, USA: Wiley-Blackwell; 2016.

6 Uwagawa T, Misawa T, Tsutsui N, Ito R, Gocho T, Hirohara S, Sadaoka S and Yanaga K: Phase II study of gemcitabine in combination with regional arterial infusion of nafamostat mesilate for advanced pancreatic cancer. Am J Clin Oncol 36: 44-48, 2013. PMID: 22157216. DOI: 10.1097/COC.0b013e $31823 \mathrm{a} 53 \mathrm{~b} 2$

7 Sakamoto T, Saito H, Uchinaka EI, Morimoto M, Amisaki M, Tokuyasu N, Honjo S, Ashida K and Fujiwara Y: The combination of neutrophil-to-lymphocyte ratio and serum carbohydrate antigen 19-9 level as a prognostic indicator in patients with recurrent pancreatic cancer. Anticancer Res 38: 5497-5503, 2018. PMID: 30194208. DOI: 10.21873/anticanres. 12883

8 Yamada D, Eguchi H, Iwagami Y, Asaoka T, Noda T, Kawamoto $\mathrm{K}$, Gotoh K, Kobayashi S, Mori $\mathrm{M}$ and Doki $\mathrm{Y}$ : The investigation of the survival time after recurrence in patients with pancreatic ductal adenocarcinoma for individualization of adjuvant chemotherapy. Surg Today 48: 952-962, 2018. PMID: 29770847. DOI: $10.1007 / \mathrm{s} 00595-018-1674-3$

9 Groot VP, Rezaee N, Wu W, Cameron JL, Fishman EK, Hruban RH, Weiss MJ, Zheng L, Wolfgang CL and He J: Patterns, 
timing, and predictors of recurrence following pancreatectomy for pancreatic ductal adenocarcinoma. Ann Surg 267: 936-945, 2018. PMID: 28338509. DOI: 10.1097/SLA.0000000000002234

10 Kim S, Itchins M, Arena J, Nahm C, Pavlakis N, Clarke S, Gill A, Samra $J$ and Mittal A: Patterns and determinants of recurrence for pancreatic ductal adenocarcinoma after resection. JOP 18: 458-464, 2017.

11 Shibata K, Matsumoto T, Yada K, Sasaki A, Ohta M and Kitano S: Factors predicting recurrence after resection of pancreatic ductal carcinoma. Pancreas 31: 69-73, 2005. PMID: 15968250. DOI: 10.1097/01.mpa.0000166998.04266.88

12 Ariake K, Motoi F, Ohtsuka H, Fukase K, Masuda K, Mizuma M, Hayashi H, Nakagawa K, Morikawa T, Maeda S, Takadate T, Naitoh T, Egawa S and Unno M: Predictive risk factors for peritoneal recurrence after pancreatic cancer resection and strategies for its prevention. Surg Today 47: 1434-1442, 2017. PMID: 28434080. DOI: 10.1007/s00595-017-1531-9

13 Furukawa K, Shiba H, Shirai Y, Horiuchi T, Iwase R, Haruki K, Fujiwara Y, Misawa $\mathrm{T}$ and Yanaga $\mathrm{K}$ : Negative impact of preoperative endoscopic biliary drainage on prognosis of pancreatic ductal adenocarcinoma after pancreaticoduodenectomy. Anticancer Res 35: 5079-5083, 2015. PMID: 26254410.

14 Von Hoff DD, Ervin T, Arena FP, Chiorean EG, Infante J, Moore M, Seay T, Tjulandin SA, Ma WW, Saleh MN, Harris M, Reni M, Dowden S, Laheru D, Bahary N, Ramanathan RK, Tabernero J, Hidalgo M, Goldstein D, Van Cutsem E, Wei X, Iglesias J and Renschler MF: Increased survival in pancreatic cancer with nabpaclitaxel plus gemcitabine. N Engl J Med 369: 1691-1703, 2013. PMID: 24131140. DOI: 10.1056/NEJMoa1304369

15 Nishina T, Boku N, Gotoh M, Shimada Y, Hamamoto Y, Yasui $\mathrm{H}$, Yamaguchi K, Kawai H, Nakayama N, Amagai K, Mizusawa J, Nakamura K, Shirao K and Ohtsu A; Gastrointestinal Oncology Study Group of the Japan Clinical Oncology Group:
Randomized phase II study of second-line chemotherapy with the best available 5-fluorouracil regimen versus weekly administration of paclitaxel in far advanced gastric cancer with severe peritoneal metastases refractory to 5-fluorouracilcontaining regimens (JCOG0407). Gastric Cancer 19: 902-910, 2016. PMID: 26386560. DOI: 10.1007/s10120-015-0542-8

16 Takashima A, Shitara K, Fujitani K, Koeda K, Hara H, Nakayama N, Hironaka S, Nishikawa K, Kimura Y, Amagai K, Fujii H, Muro K, Esaki T, Choda Y, Takano T, Chin K, Sato A, Goto M, Fukushima N, Hara T, Machida N, Ohta M, Boku N, Shimura M, Morita S and Koizumi W: Peritoneal metastasis as a predictive factor for nab-paclitaxel in patients with pretreated advanced gastric cancer: an exploratory analysis of the phase III ABSOLUTE trial. Gastric Cancer 22: 155-163, 2019. PMID: 29855738. DOI: 10.1007/s10120-018-0838-6

17 Ettrich TJ, Berger AW, Perkhofer L, Daum S, König A, Dickhut A, Wittel U, Wille K, Geissler M, Algül H, Gallmeier E, Atzpodien J, Kornmann M, Muche R, Prasnikar N, Tannapfel A, Reinacher-Schick A, Uhl W and Seufferlein T: Neoadjuvant plus adjuvant or only adjuvant nab-paclitaxel plus gemcitabine for resectable pancreatic cancer - the NEONAX trial (AIO-PAK0313), a prospective, randomized, controlled, phase II study of the AIO pancreatic cancer group. BMC Cancer 18: 1298, 2018. PMID: 30594153. DOI: 10.1186/s12885-018-5183-y

Received November 20, 2019

Revised November 26, 2019

Accepted November 27, 2019 